\title{
Influence of Textile Structure and Silica Based Finishing on Thermal Insulation Properties of Cotton Fabrics
}

\author{
G. Rosace, E. Guido, C. Colleoni, and G. Barigozzi \\ Department of Engineering and Applied Sciences, University of Bergamo, Viale Marconi 5, Dalmine, 24044 Bergamo, Italy \\ Correspondence should be addressed to G. Rosace; giuseppe.rosace@unibg.it
}

Received 22 December 2015; Revised 10 February 2016; Accepted 14 February 2016

Academic Editor: Nabil Ibrahim

Copyright (c) 2016 G. Rosace et al. This is an open access article distributed under the Creative Commons Attribution License, which permits unrestricted use, distribution, and reproduction in any medium, provided the original work is properly cited.

\begin{abstract}
The aim of this work is to investigate the influence of weave structures and silica coatings obtained via sol-gel process on the thermal insulation properties of cotton samples. For this reason three main weave structures (plain, satin, and piqué) of cotton fabric were selected with different yarn count, threads per $\mathrm{cm}$, and mass per square meter values. Thereafter, only for the plain weave, the samples were padded using silica sol formed by hydrolysis and subsequent condensation of 3-glycidoxypropyltrimethoxysilane under acidic conditions. The silanized plain weave samples were characterized by TGA and FT-IR techniques. The thermal properties were measured with a home-made apparatus in order to calculate thermal conductivity, resistance, and absorption of all the treated fabric samples. The relationship between the thermal insulation properties of the plain weave fabrics and the concentration of sol solutions has been investigated. Fabrics weave and density were found to strongly influence the thermal properties: piqué always shows the lowest values and satin shows the highest values while plain weave lies in between. The thermal properties of treated high-density cotton plain weave fabric were proved to be strongly influenced by finishing agent concentration.
\end{abstract}

\section{Introduction}

In the last decade, the advent of nanotechnologies has spurred significant development and innovation in the field of textile technology. Fabric finishing has taken new routes and demonstrated a great potential for significant improvements of surface functionalization by nanoparticles [1], plasma [2, 3], and sol-gel products [4]. Thanks to the nature of the fibres, as well as the choice of the most relevant manufacturing techniques including finishing processes, technical textile producers are able to propose textile solutions offering mechanical, exchange, or protective properties, suited to the specific needs of the final users. Particularly, sol-gel represents a versatile synthetic route to get these properties. It is a two-step reaction (hydrolysis and condensation) that, starting from (semi)metal alkoxides (e.g., tetraethoxysilane, tetramethoxysilane, and titanium tetraisopropoxide), leads to the formation of completely inorganic or hybrid organicinorganic coatings at or near room temperature [5]. These porous coatings are capable of protecting the polymer surface by creating a physical barrier acting as insulator, thus improving some specific properties, like flame retardancy, water or oil repellency, and wear resistance [4]. As far as textile applications are concerned, usually the sol-gel technique has been proposed for conferring new functional properties to fabrics, such as antimicrobial or UV radiation protection $[6,7]$, dye fastness [8,9], antiwrinkle finishing [10], and hydrophobicity [11]. Recently, we have published some papers on innovative sol-gel route for developing wearable sensor [12] and antibacterial finishing [13] and on the possibility of reducing the flammability [14], also trying to assess phosphorus-nitrogen synergisms [15-17]. Due to the porous structure of the solgel based coatings, the finishing can affect the thermal insulating properties, particularly those related to the IR thermal radiation [18].

The literature reports several papers focused on the influence of fibre morphology, yarn, and fabric structure on thermal properties [19-21]. Generally, the way textile physiological properties (including thermal properties) are measured is established by the European Standard UNI EN 31092 [22]. This code is based on the use of a steady-state device, the so-called "Skin Model," simulating the heat and humidity exchanged through the clothes between the human body 
TABLE 1: CO samples structural characteristics.

\begin{tabular}{lcccccc}
\hline Sample code & Ends/cm & Picks/cm & \multicolumn{2}{c}{ Linear density (tex) } & Weave & $\begin{array}{c}W \\
{[\mathrm{~mm}]}\end{array}$ \\
\hline CO-1 & 27 & 24 & 11.8 & 11.8 & Plain & 0.17 \\
CO-2 & 30 & 30 & 19.7 & 19.7 & Plain & 0.25 \\
CO-3 & 36 & 36 & 14.8 & 14.8 & Plain & 0.22 \\
CO-4 & 66 & 32 & 10.2 & 9.6 & Satin & 0.25 \\
CO-5 & 72 & 36 & 9.8 & 9.8 & Satin & 0.33 \\
CO-6 & 90 & 51 & 8.4 & 13.9 & Satin & 0.28 \\
CO-7 & 36 & 30 & 29.5 & 22.2 & Piqué & 105 \\
CO-8 & 72 & 36 & 14.8 & 22.2 & Piqué & 1.13 \\
CO-9 & 72 & 36 & 14.8 & 22.2 & Piqué & 340 \\
\hline
\end{tabular}

and the environment. In the open literature many papers are focused on the development of instrumentations devoted to the measurement of thermal insulation and comfort properties of textile fabrics and clothing. Similar to the Skin Model, some of the proposed approaches are based on the establishment of a steady-state thermal conductivity regime where an electric heater creates a temperature field in a sample [23]. Others make use of a transient experiment. Among them, the Alambeta device [24] allows measuring the textile thermal contact properties necessary for the definition of the so-called warm/cool feeling. This instrumentation was successfully applied $[25,26]$ for the characterization of several kinds of textile fabrics, taking into account the effect of different fabric covering factors and finishing agents. Beside the Alambeta device, in the last years, other experimental apparatus were proposed to test the thermal comfort of textile fabrics, like the "hot disk" [27] and the FRMT (fabric radiation management tester) [28] devices. All these methods have the disadvantage of measuring the fabric surface temperature in a single point, thus assuming a uniform temperature distribution over the textile surface. This is not the case for fabrics characterized by low covering factors, presenting highly variable temperature values over their structure. For this reason, an experimental apparatus [29], recently developed by our research group, was used in this work. It is similar to the hot disk mentioned above but takes advantage of the use of an IR Thermocamera to measure the whole fabric surface temperature distribution. By means of this apparatus, this research aims to investigate the influence of three main cotton fabric weaves (plain, satin, and piqué), selected with different yarn count, threads per $\mathrm{cm}$, and mass per square meter values, on the thermal conductivity of cotton textile fabrics. Moreover, limiting the investigation to plain weave samples, the same measurement was extended to study the influence of 3-glycidoxypropyltrimethoxysilane (GPTMS) precursor, used to coat the selected textile pattern with a hybrid organic-inorganic film. Compared with other sol-gel precursors, GPTMS is an organically modified alkoxide, in which the organic group contains an epoxide ring that can be cross-linked to form a poly(ethylene oxide) chain and acts, therefore, as network promoter. The relevance of this silica coating, as a function of precursor concentration, on plain cotton samples was investigated in this study.

\section{Materials and Methods}

2.1. Materials. To evaluate the influence of structural characteristics on thermal conductivity related properties, cotton (CO) fabrics reported in Table 1 were evaluated in this study.

Woven fabrics are formed by interlacing two orthogonal sets of yarns: warp yarns that are vertically arranged and weft yarns that are horizontally placed. Since all weave structures are created from a binary system (i.e., a warp yarn is over or under a weft yarn at the crossover areas), infinite number of weaves can be formed. The geometric structure of the woven fabric affects mechanical, thermal, and electrical properties, as well as aesthetical effects of the fabric. Besides the classical plain weave (Figure 1(a)), where each filling yarn passes successively over and under each warp yarn, alternating each row, also satin-weave and piqué fabrics were considered. In satin-weave fabrics (Figure 1(b)), the face of the fabric consists almost completely of warp or filling floats produced in the repeat of the weave. The points of intersection are distributed evenly and widely separated as possible. Satinweave fabric has a considerably greater number of yarns in the set of threads, either warp or filling. Finally, piqué is a double cloth with two warps and two filling yarns, one fine and one heavy. It is a medium weight to heavyweight fabric with raised cords in the warp direction (Figure 1(c)).

The fabrics were washed in $2 \%$ nonionic detergent (Berdet WF, wetting agent, kindly supplied by Europizzi, Urgnano, Italy) at $\mathrm{pH} 7$ and $40^{\circ} \mathrm{C}$ for $20 \mathrm{~min}$, then rinsed several times with deionized water, and dried and stored under standard atmospheric pressure at $65 \pm 4 \%$ relative humidity and $20 \pm 2^{\circ} \mathrm{C}$ for at least $24 \mathrm{~h}$ prior to all the experiments. They were finally cut into samples: one $(30 \mathrm{~cm} \times 30 \mathrm{~cm})$ for thermal conductivity assessment, one $(5 \mathrm{~cm} \times 5 \mathrm{~cm})$ for thickness and mass evaluation, and when required, three $(30 \mathrm{~cm} \times 30 \mathrm{~cm})$ for finishing influence analysis. Besides the textiles main structural characteristics and composition, Table 1 also reports the thickness $\sigma$ and the mass per unit area $W$ values. Fabric thickness was measured following UNI EN ISO 5084 [30] with an 
TABLE 2: Investigated sol formulations.

\begin{tabular}{lcccccc}
\hline \multirow{2}{*}{ Sol concentrations $(\mathrm{g} / \mathrm{L})$} & \multirow{2}{*}{ GPTMS $(\mathrm{g})$} & $\mathrm{HCl}(\mathrm{mL})$ & $\mathrm{H}_{2} \mathrm{O}(\mathrm{mL})$ & \multicolumn{3}{c}{ Final add-on (\%) } \\
\hline 50 & 50 & 40 & 913 & 2.7 & CO-2 & CO-3 \\
100 & 100 & 40 & 867 & 5.3 & 5.9 & 2.9 \\
200 & 200 & 40 & 773 & 8.9 & 10.5 & 5.7 \\
\hline
\end{tabular}

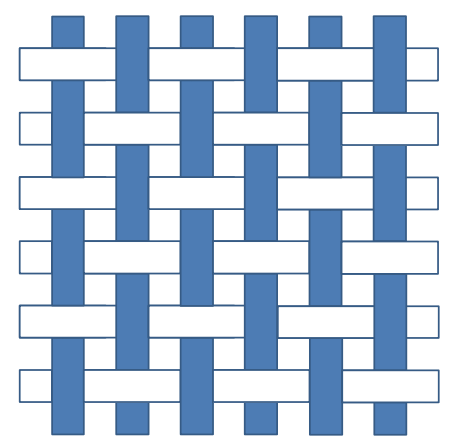

(a)
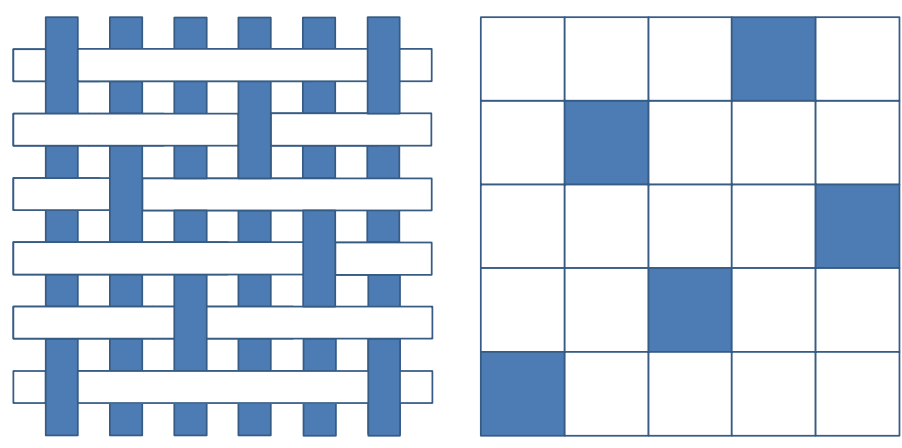

(b)
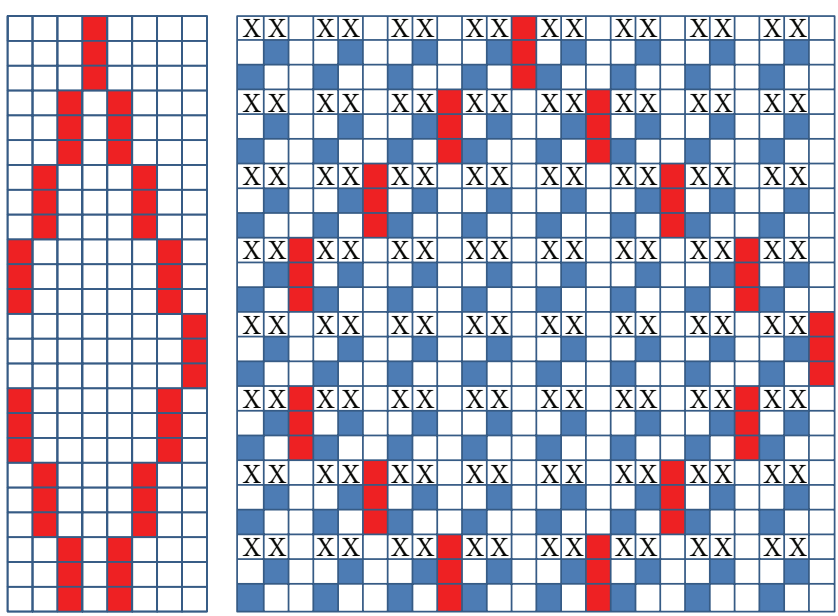

(c)

FIGURE 1: Weave repeats in flat view and equivalent weave patterns of plain (a), satin (b), and piqué ((c), simplified sketch) fabrics.

uncertainty of $\pm 0.001 \mathrm{~mm}$, while mass per unit area was determined according to UNI EN 12127 [31] using a gravimetric methodology.

2.2. Sol Preparation and Application. 3-Glycidoxypropyltrimethoxysilane (GPTMS, sol-gel precursor) and other chemicals were purchased from Sigma Aldrich and used as received. The sols for the impregnation of cotton fabrics were synthesized according to the molar ratios shown in Table 2. A certain amount of GPTMS was hydrolyzed separately with $\mathrm{HCl}$ $(0.1 \mathrm{~N})$ in deionized water under vigorous stirring for $12 \mathrm{~h}$ at room temperature to obtain one litre for each silica based sol. The amount of $\mathrm{HCl}$, large enough to promote the hydrolysis of all precursor solutions, was set at $40 \mathrm{~g} / \mathrm{L}$ to avoid the fact that higher concentration of acid could damage the textile fabric during curing process. As a result, clear solutions were obtained for all concentrations. Long-term stability was also tested. After being stored for several weeks, no significant changes of properties were observed.

The cotton fabrics $(30 \mathrm{~cm} \times 30 \mathrm{~cm})$ were impregnated with three different concentrations $(50 \mathrm{~g} / \mathrm{L}, 100 \mathrm{~g} / \mathrm{L}$, and $200 \mathrm{~g} / \mathrm{L}$ ) of GPTMS sols and afterward passed through a tworoll laboratory padder (Werner Mathis, Zurich, Switzerland) working with a 3-bar nip pressure as to obtain about $75-85 \%$ of wet pickup. After drying at $80^{\circ} \mathrm{C}$ for $5 \mathrm{~min}$, the fabrics were thermally treated at $170^{\circ} \mathrm{C}$ for $4 \mathrm{~min}$ in a gravity convection oven. The finished samples were finally conditioned under standard condition for $24 \mathrm{~h}$ before the test starts. 


\subsection{Characterization Techniques}

2.3.1. FT-IR Characterization. FT-IR spectra were acquired by means of a Thermo Avatar 370 spectrometer equipped with an attenuated total reflection (ATR) accessory. A diamond crystal was used as internal reflectance element on the ATR accessory. Spectra were recorded at room temperature, in the range from 4000 to $700 \mathrm{~cm}^{-1}$, acquiring 32 scans per data set at a $4 \mathrm{~cm}^{-1}$ resolution. Two spectra were recorded for each sample. Average spectra were normalized to the band at $1315 \mathrm{~cm}^{-1}\left(\mathrm{CH}_{2}\right.$ wagging of cellulose), which falls in a region where siloxane absorptions are absent.

2.3.2. Thermogravimetric Analysis (TGA). Thermogravimetric analysis (TGA) was carried out on a TA Instruments Model TGA Q500 operating under $\mathrm{N}_{2}$ atmosphere in the range $30-600^{\circ} \mathrm{C}$, with a heating rate of $10^{\circ} \mathrm{C} / \mathrm{min}$ and $60 \mathrm{~mL} /$ min gas flow.

2.3.3. Thermal Conductivity Characterization. Thermal conductivity $\lambda(\mathrm{W} / \mathrm{m} \cdot \mathrm{K})$ was measured by means of a hot disk based device, imposing a known constant heat flux $\dot{Q}(\mathrm{~W})$ through the tested samples and measuring the temperature difference $\Delta T(\mathrm{~K})$ across its thickness:

$$
\dot{Q}=\frac{A \lambda \Delta T}{\sigma},
$$

with $A\left(\mathrm{~m}^{2}\right)$ being the sample surface. The experimental setup was thus designed to provide measurement of the cooling rate of a solid body heated to a fixed temperature and insulated from the ambient medium by the fabric. The schematic diagram of the experimental apparatus, named TheCotex, is shown in Figure 2.

It consists of a heating device, that is, a hot plate, that can be moved inside an externally insulated poly(methyl methacrylate) (PMMA) cylinder, on the top of which the fabric sample is installed, thus separating the hot cylindrical cavity from the ambient air. In the present study the hot plate was directly in contact with the textile sample. To avoid any air remaining entrapped between the hot disk and the sample, and to limit lateral heat conduction, each sample was first installed in between two $35 \mathrm{~mm}$ thick square PMMA hollow platforms located on the top of the cylinder (see Figure 2). The hot disk is then moved upward inside of the cylinder: during measurement, the hot plate was kept under the same constant pressure for all samples against the surface of the fabric in order to ensure maximum adhesion and prevent the presence of air between both surfaces without influencing the textile structure. The test section is located in the middle of the plate, surrounded by the PMMA insulation. With this setup, the specimen to be tested is placed over the entire surface of the hot plate in a flat condition and the heat flux from the plate to the environment is measured once steady-state condition is reached. It is a dry test, as the hot plate produces heat but does not produce moisture. Such an arrangement better simulates the conditions of use in which the heat is supplied by the human body on one side of the fabric and transferred to the air on the other side. As the hot plate
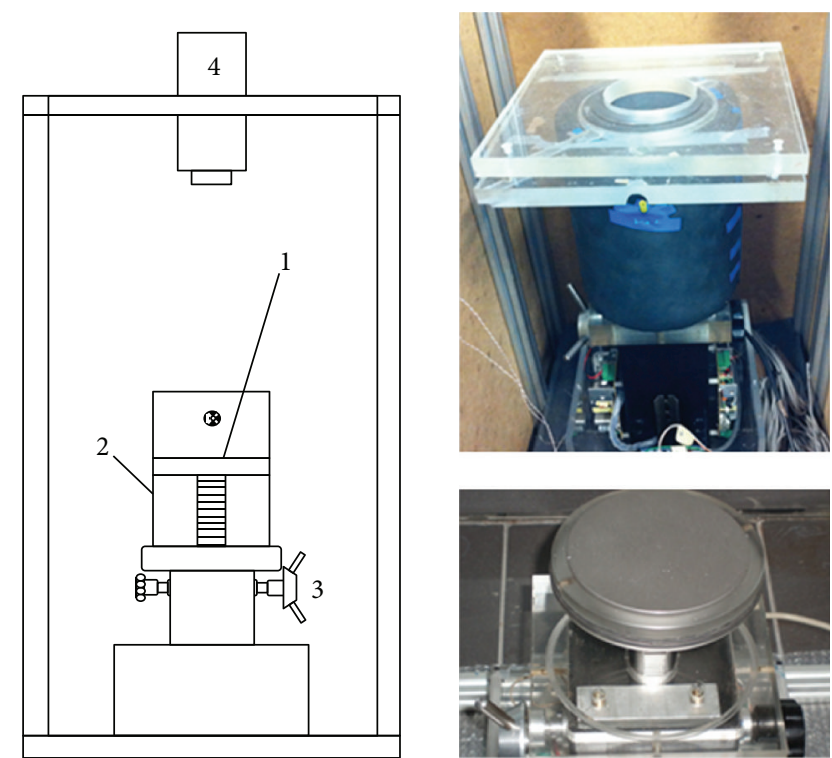

FIgURE 2: A view of the TheCotex apparatus: (1) hot plate; (2) PMMA cylinder; (3) control mechanism for raising/lowering the hot plate; (4) IR Thermocamera.

was directly in contact with the textile sample, the plate temperature, measured by means of calibrated T-type thermocouples, corresponds just to the bottom temperature of the sample. The top external surface temperature was measured using an IR Thermocamera (FLIR ThermoVision ${ }^{\mathrm{TM}}$ A40 with a $64 / 150 \mathrm{~mm}$ close-up lens), allowing capturing the textile sample surface temperature distribution $\left( \pm 0.08^{\circ} \mathrm{C}\right.$ thermal sensitivity at $30^{\circ} \mathrm{C}$ ) over a $64 \mathrm{~mm} \times 24 \mathrm{~mm}$ area. Moreover, other T-type thermocouples are glued to the external surface of the sample for calibration purposes. Due to heat losses through the ambient air and the plate support, the heat power could differ from the measured electrical power. To quantify the relationship between the actual thermal heat $Q$ from the hot plate to the fabric sample and the measured electric power, a calibration was performed by using a calorimeter. This procedure led to the definition of a correction curve. The heat flux across the sample is thus calculated starting from the electric power dissipated into the hot plate, applying the correction derived from calibration. Surface thermocouples were also used to calibrate the IR Thermocamera. In fact, the uncertainty in the temperature measured by an IR Thermocamera highly depends mostly on two parameters: the reflected temperature and the emissivity of the surface. To minimize the influence of reflected temperature, all measurements were performed in the dark. Concerning the emissivity, each sample was first calibrated by selecting the emissivity value that assures the coincidence between the temperature values measured in selected locations by both thermocouples and IR Thermocamera. In the present investigation the plate temperature was maintained at about $36^{\circ} \mathrm{C}$ by an automatic control system that allows maintaining the hot plate temperature at the desired working point with an accuracy of $\pm 0.1 \%$ and a stability of $\pm 0.1^{\circ} \mathrm{C}$. Once the system is in thermal equilibrium, the data acquisition is started. 
To improve measurement accuracy, five repeated tests were performed on each sample and results averaged. Moreover, during each test, all temperature values were obtained by averaging over 100 data sets. The resulting thermal conductivity measurement uncertainty was estimated to be about $\pm 10 \%$ with $\lambda=0.05 \mathrm{~W} / \mathrm{m} \cdot \mathrm{K}$. More details on measurement setup, data acquisition, and processing procedures and on device calibration are given in [29]. From the measured thermal conductivity $\lambda$, thermal comfort related properties like thermal resistance $R$ and absorption $b$ were computed as follows $[25,32]:$

$$
\begin{aligned}
& R=\frac{\sigma}{\lambda} \\
& b=\sqrt{\sigma \rho c},
\end{aligned}
$$

where $\rho\left(\mathrm{kg} / \mathrm{m}^{3}\right)$ is the sample density and $c(\mathrm{~J} /(\mathrm{kg} \cdot \mathrm{K}))$ its specific heat.

It is worth to note that the way finishing is expected to influence thermal absorption is through a modification of thermal conductivity and/or the heat capacity $\rho \cdot c$. The last parameter cannot be directly measured with the present setup, requiring at least a transient experiment. For this reason thermal absorption related data are only presented for untreated samples, considering a constant specific heat of $1.34 \mathrm{~J} / \mathrm{kg} \cdot \mathrm{K}$ (density variations are directly measured). Of course different textile structures, entrapping different amount of air, will be in principle characterized by different values of $c$. This approach thus only considers the impact of density variation, neglecting the one of specific heat. As porosity is supposed to increase from satin to plain up to piqué, the corresponding specific heat would decrease accordingly. Also considering the specific heat variation would have led to progressively slightly lower thermal absorption levels for satin, plain, and piqué, according to (2). Finally, when considering the effects of finishing, only thermal resistance will be considered besides thermal conductivity.

\section{Results and Discussion}

3.1. Infrared Spectroscopy (ATR FT-IR). In view of the application of silane films on textile substrate, the hydrolysis of alkoxysilanes has an important influence on final properties of the sol-gel film. In fact, when applied, the silanol groups of hydrolyzed silane interact not only among themselves (intracondensation) but also with the hydroxyl groups (Cell-OH) on cellulose material (intercondensation) through temporary weak hydrogen bonding. The formation of strong covalent cellulose-siloxane bonds takes place during subsequent drying and curing, providing a very compact network of several orders of microns thus protecting the treated surface [33]. In order to verify the deposition of sol-gel based film onto textile fabrics, FT-IR ATR investigation was performed onto cotton samples. IR spectroscopy is a consolidated technique that is used to confirm the cellulose surface silanization, monitoring Si-O-Si bond formation. Many researches have shown that it is possible to use the $\mathrm{Si}-\mathrm{O}-\mathrm{Si}$ region to confirm

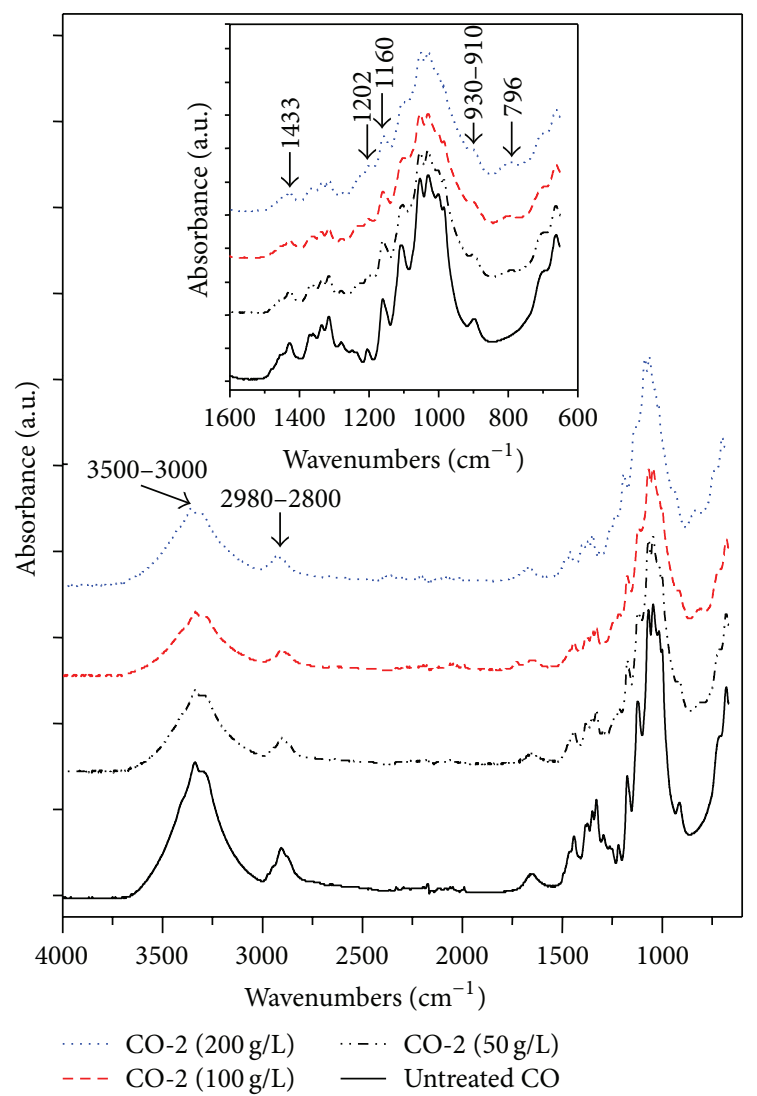

FIGURE 3: ATR FT-IR spectra of untreated cotton and treated cotton samples with GPTMS at $50 \mathrm{~g} / \mathrm{L}, 100 \mathrm{~g} / \mathrm{L}$, and $200 \mathrm{~g} / \mathrm{L}$.

network between covalently bound organosilanes through $\mathrm{Si}$ O-Si surface bonds deposited on the treated surfaces [14-16, $34,35]$. Regarding this study, the infrared absorption spectra of the untreated and treated cotton fabrics by $50 \mathrm{~g} / \mathrm{L}, 100 \mathrm{~g} / \mathrm{L}$, and $200 \mathrm{~g} / \mathrm{L}$ sol solutions are shown in Figure 3. The spectra of the treated textiles were compared with the substrate of untreated cotton in order to more easily locate the characteristic peaks of the sol deposited, which have been shown to be small but significant. Due to the same chemical structure of cellulose-based samples involved in the present study, the investigation was carried out only onto plain weave fabric.

The infrared absorption bands in the ranges 3500$3000 \mathrm{~cm}^{-1}, 2980-2800 \mathrm{~cm}^{-1}$, and $1433-1428 \mathrm{~cm}^{-1}$, characteristic of hydrogen bonded $\mathrm{O}-\mathrm{H}$ stretching, $\mathrm{C}-\mathrm{H}$ stretching, and $\mathrm{C}-\mathrm{H}$ wagging of cellulose, respectively, remained essentially unchanged as shown by the spectra of the treated fabrics. The presence of the thin silicon film covering the surface of cotton fibres is strongly evidenced by a significant intensity increase in the fingerprint spectral region at $<1300 \mathrm{~cm}^{-1}$, due to overlapping of the main cellulose and silicon absorptions. The effect is particularly evident for the cotton fabrics treated with highest GPTMS concentration, as expected from the higher thickness of the film deposited onto the fabric surface. The spectral profile of the cellulose polymeric matrix is essentially maintained, but new bands specifically attributed to the silica xerogel appeared. The deposition of the film is 
confirmed by the presence at around $1200 \mathrm{~cm}^{-1}, 930 \mathrm{~cm}^{-1}$, and $796 \mathrm{~cm}^{-1}$ of absorption bands assigned to $\mathrm{Si}-\mathrm{O}$ stretching vibration shoulder, $\mathrm{Si}-\mathrm{OH}$ stretching, and $\mathrm{Si}-\mathrm{O}-\mathrm{Si}$ symmetric stretching, respectively. The band expected at $1018 \mathrm{~cm}^{-1}$ is overlapped with a broad band between 1050 and $980 \mathrm{~cm}^{-1}$ attributed to characteristic peaks of cellulose. A similar behavior is observed for the lower GPTMS concentrations treated fabrics, although with a general lower intensity of the spectral profiles between untreated and treated fabrics, certainly because of the lower concentration of the deposited silica finishing.

3.2. Thermogravimetric Analysis (TGA). The thermal stability of the sol-gel treated and untreated cotton samples has been assessed by thermogravimetric analysis under nitrogen atmosphere. According to the data shown in Section 3.4 about the influence of finishing onto thermal insulator properties of cotton fabrics, limited to plain weave samples, TGA was carried out only on these same samples. As well described in the literature, cotton shows a peculiar thermal degradation in nitrogen [17], due to pyrolysis according to two alternative pathways: (i) the decomposition of the glycosyl units to char at lower temperature and (ii) the depolymerization of such units to volatile products containing levoglucosan at higher temperature. TGA analysis of cotton sample reveals that the pyrolysis of cellulose fibre includes three stages: initial, main, and char decomposition. In the initial step, where the temperature range is below $300^{\circ} \mathrm{C}$, the most important changes of the fibres are some physical properties and little weight loss. The main pyrolysis phase occurs in the temperature range of $280-$ $340^{\circ} \mathrm{C}$. In this stage, the weight loss is very fast and significant. Most of pyrolysis products are produced in this stage, as LGlucose, which is one of the major products, together with all kinds of combustible gases. The char pyrolysis occurs at the temperature above $400^{\circ} \mathrm{C}$. During this process, dewatering and charring reactions compete with the production of LGlucose, with the dewatering and charring reactions being more obvious. The mass decomposition continues producing double bond, carboxyl, and carbonyl products. The carbon content in the decomposed products progressively increases, and charred residues are formed. According to this theoretical approach, the TGA plots for treated and untreated cotton samples in nitrogen atmosphere are shown in Figure 4. Since the investigated samples are only cellulose-based polymers and very small difference was observed for the different solgel coatings, TGA was carried out comparing pure cotton and the silanized plain weave cotton samples. As expected, the TGA curves of these samples were very similar also due to the similar final add-on (\%) of samples CO-1, CO-2, and CO-3 (Table 2). In order to avoid overlapping curves and to allow a good readability of the thermogravimetric data, in Figure 4, only thermograms of untreated and treated CO-2 cotton fabrics at variable concentration are shown. CO-2 samples were selected because they gave slightly more relevant results from TGA, since the final add-on is slightly higher than the others, whatever the concentration. In relation to the untreated cotton, the first weight loss at about $100^{\circ} \mathrm{C}$ was about $5 \%$ corresponding to water release present in the

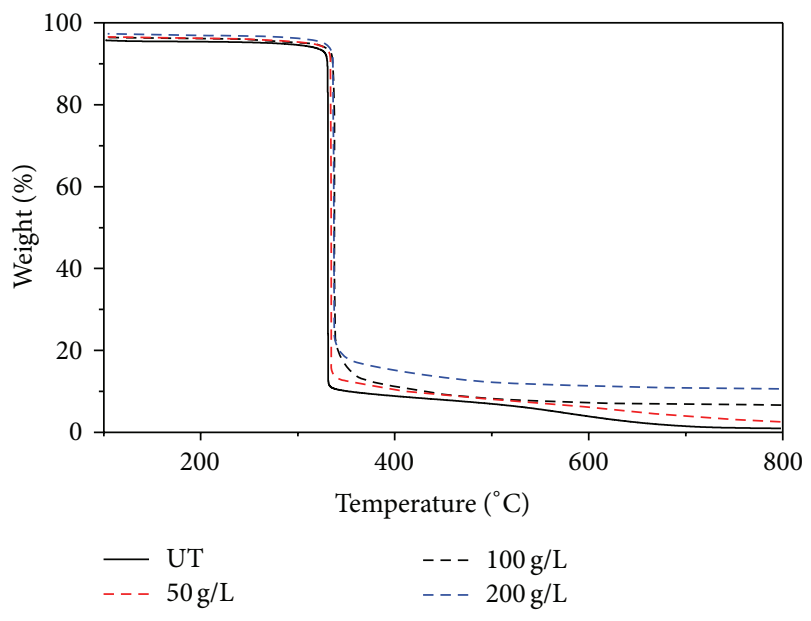

FIGURE 4: TGA thermograms of untreated and treated CO-2 cotton fabrics.

sample due to the moisture content. The second weight loss, observed at about $340^{\circ} \mathrm{C}$, was about $85 \mathrm{wt} \%$ corresponding to thermal degradation of cotton. Finally, during the third stage the char yield is almost null for the untreated cotton sample. The pyrolysis of the silica-covered cellulose fibres shows the similar three stages but with lower weight loss than that of the untreated cellulose; thus the high char production confirms the presence of the film onto textile fabric. This result shows that the silica coatings are able to favour the char formation, limiting the production of volatile species. Furthermore, it is clear that char amount increases when increasing the add-on of sol-gel finishing. More specifically, comparing treatment realized with $50 \mathrm{~g} / \mathrm{L}, 100 \mathrm{~g} / \mathrm{L}$, and $200 \mathrm{~g} / \mathrm{L}$, it is clear that the higher residue is ascribable to the higher concentration of silica finishing.

\subsection{Influence of Weave on CO Fabrics Insulation Properties.} Figure 5 reports as an example some of the recorded IR images belonging to the three different weaves tested: plain, satin, and piqué (see Table 1). Pictures show the fabric surface temperature distribution in false colours: temperature scale for the three images is the same. As clearly shown, the different fabric structures can be clearly identified, as well as the piqué nonuniform temperature distribution. In fact temperature differences as large as $2.5^{\circ} \mathrm{C}$ between the different weave components were detected.

Figure 6 shows the influence of CO fabric density $\rho$ and weave on the measured thermal conductivity $\lambda$, resistance $R$, and absorption $b$ values. Fabric density $\rho$ was computed as the ratio between the mass per unit area $W$ and thickness $\sigma$ values reported in Table 1. As a general comment, one can observe that the measured values are consistent with others available in the open literature [32]. First considering the influence of weave structure, piqué always shows the lowest values of all thermal properties but the thermal resistance and satin the highest while plain weave lies in between. Piqué thermal resistance $R$ values (Figure 6(b)) linearly decrease with rising density, while satin and plain fabric data remain practically unchanged and one order of magnitude lower. Piqué CO 


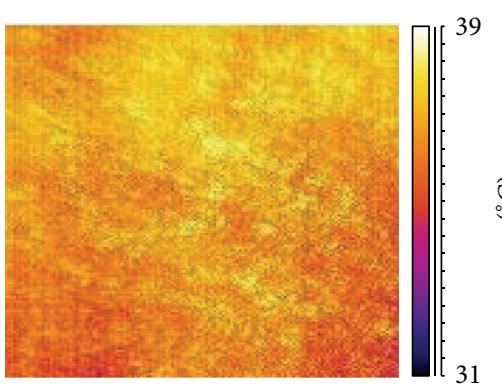

(a)

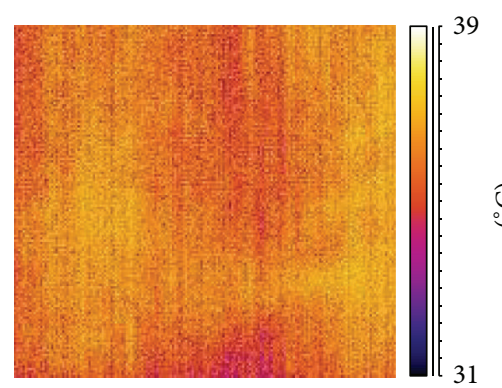

(b)

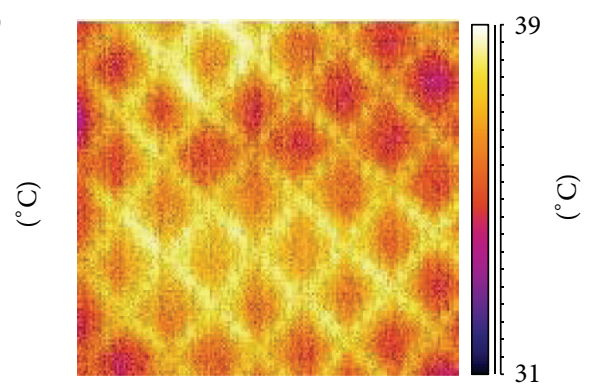

(c)

FIGURE 5: IR images of CO fabrics: (a) plain, (b) satin, and (c) piqué.

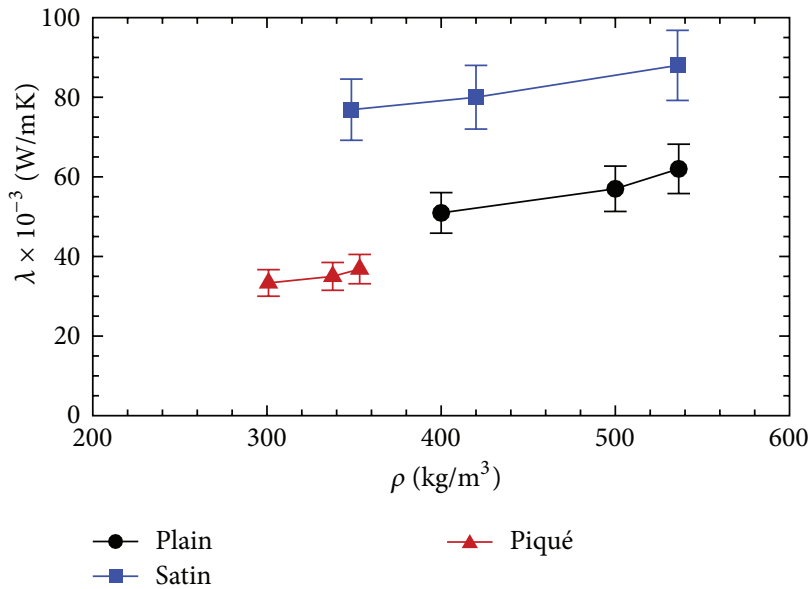

(a)

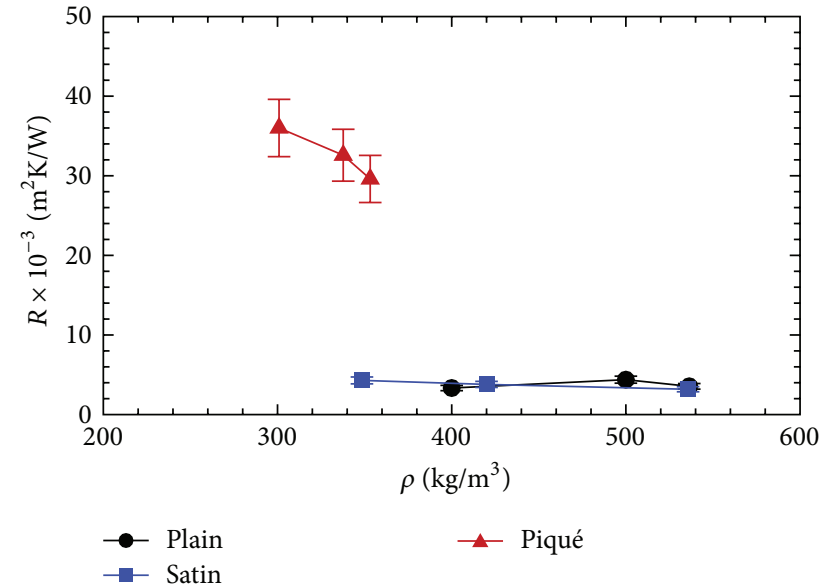

(b)

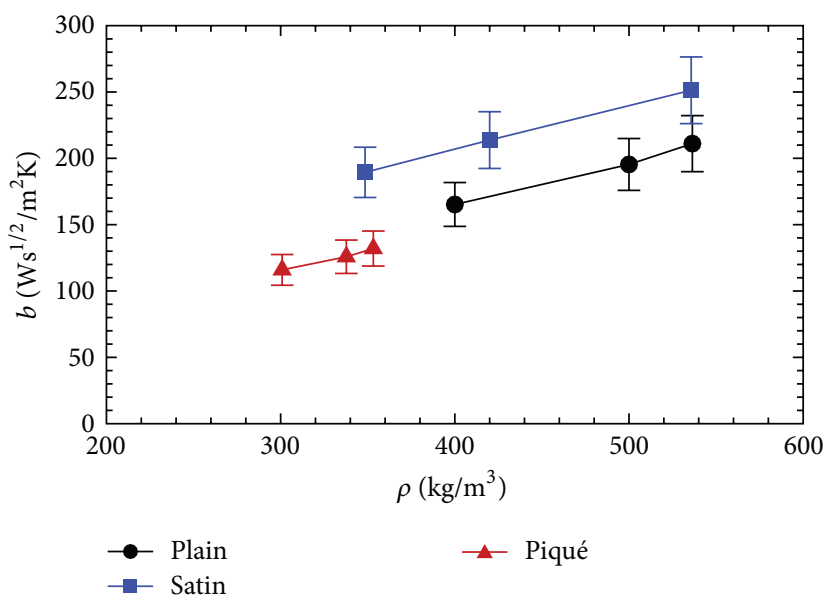

(c)

FIGURE 6: CO fabrics thermal properties versus density: (a) thermal conductivity, (b) resistance, and (c) absorption.

fabric thus presents quite good thermal insulation properties, thanks to its higher thickness and weight, but lower density, when compared to the other fabrics. Finally, as expected, the thermal absorption $b$ (Figure 6(c)) increases from piqué (warmer feeling) to plain weave up to satin (cooler feeling).

Figure 7 shows the recorded IR images belonging to the three tested piqué CO fabrics. Also reported are the corresponding density values. Again, each picture represents the surface temperature distribution in false colours. These pictures allow appreciating the relevance, for this kind of textile structure, of temperature variation over the sample surface. According to the previous quantitative analysis based on mean quantities, the first sample (CO-6), that is, the one with a high thickness coupled with a low mass per unit area, resulting in the lower tested density, shows the highest temperature variation but also the lower surface temperature 


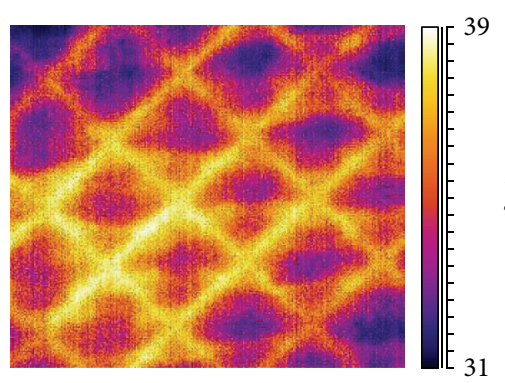

(a)

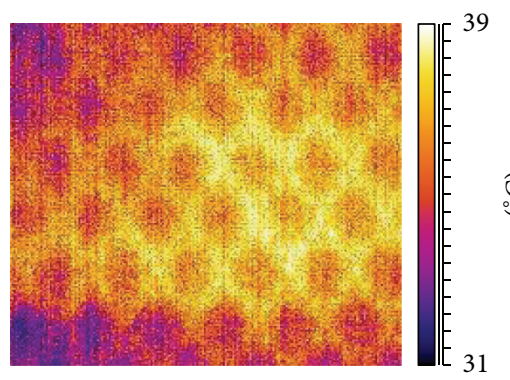

(b)

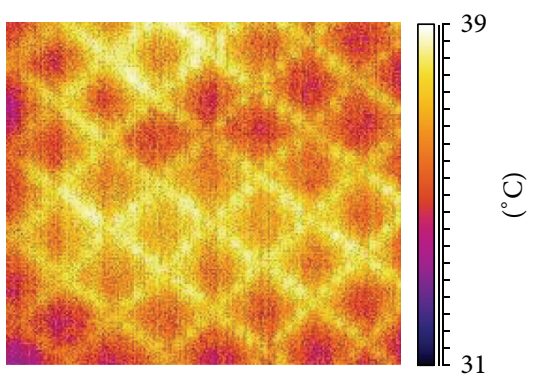

(c)

Figure 7: IR images of CO piqué fabrics: (a) CO-6 $\left(\rho=301 \mathrm{~kg} / \mathrm{m}^{3}\right)$, (b) CO-7 $\left(\rho=353 \mathrm{~kg} / \mathrm{m}^{3}\right)$, and (c) CO-8 $\left(\rho=338 \mathrm{~kg} / \mathrm{m}^{3}\right)$.

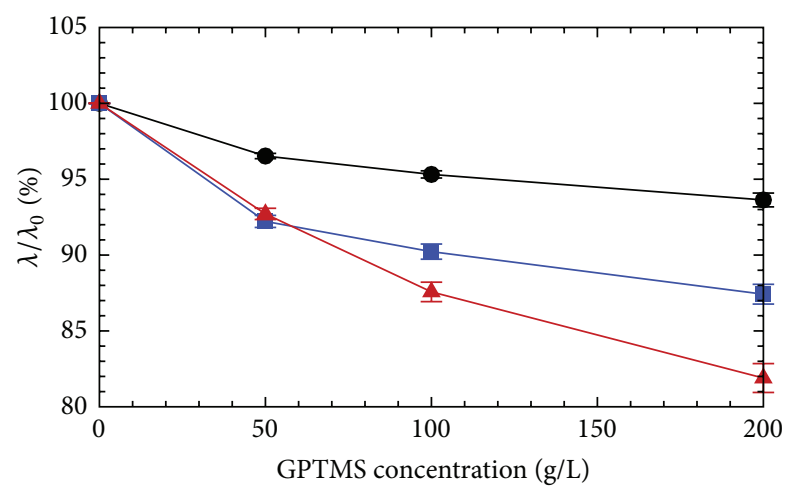

$\rightarrow \mathrm{CO}-1$

$-\mathrm{CO}-3$

(a)

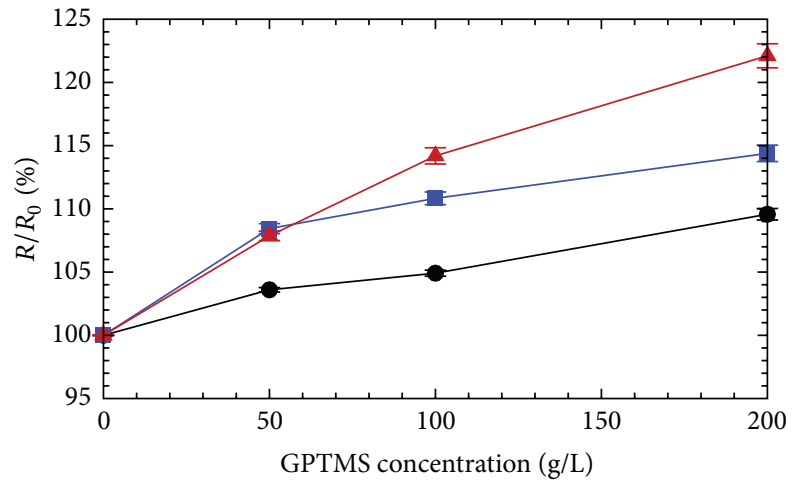

$\neg \mathrm{CO}-3$

(b)

FIGURE 8: GPTMS concentrations influence on plain CO fabrics thermal properties: thermal conductivity (a) and resistance (b).

values when compared to the other samples. This is due to the higher air entrapped inside of the texture.

\subsection{Influence of Finishing on Plain Weave CO Fabrics Thermal} Properties. The last step of this investigation was devoted to the analysis of the influence of finishing agent based on 3glycidoxypropyltrimethoxysilane precursor at three different concentrations, on $\mathrm{CO}$ plain weave fabrics thermal properties. Figure 8 shows the percentage variation of thermal conductivity and resistance for the three considered plain weave CO fabrics and increasing GPTMS concentrations. As very similar results were also obtained for the two other considered weave structures, satin and piqué, data belonging to these two kinds of $\mathrm{CO}$ fabrics are not shown here, and the whole discussion is only based on plain weave sample results. The only remarkable difference observed among plain, satin, and pique fabrics is in fact related to the relevance of variations induced by sol-gel finishing at variable concentration: the highest variations have been detected for piqué and the lowest for satin, with again plain weave lying in between. This is due to the different wet pickup induced by the different sample pattern. As Figure 8(a) clearly shows, whatever CO fabric is concerned, thermal conductivity decreases with rising concentration, while thermal resistance increases.
This different behavior can be easily explained by considering the equations relating $\lambda$ and $R$ (see (2)). In fact, a finishing concentration increase causes a thermal conductivity decrease that gives rise to a proportional thermal resistance increase. Now looking at the three tested CO fabrics, a different behavior can be observed, depending on their density $\rho$. Fabric density $\rho$ progressively increases from CO-1 up to CO-3 (Table 1), as well as the influence of finishing agent. A maximum decrease in $\lambda$ value of about $22 \%$ (and a corresponding $R$ increase) was observed for CO-3 at the largest tested concentration of $200 \mathrm{~g} / \mathrm{L}$. The lower density CO1 fabric instead presents a maximum decrease in $\lambda$ value of about $6 \%$, again at the largest concentration. This different behavior, being related to the fabric density, is probably due to the different capability of the three tested fabrics of combining with the finishing molecules, resulting in a thermal insulating behavior that becomes closer to the finishing agent's one. As shown in the discussed results, all the sol-gel treatments, with different levels, increase the thermal insulation value of the fabrics. This might be related to the increase in fabric thickness. In fact, according to the FT-IR and TGA characterizations, a porous insulating film was formed onto textile samples through the deposition of a hybrid silica film via sol-gel, characterized by excellent thermal insulation [36]. 
This conclusion is also in agreement with the open literature $[37,38]$, for which heat resistances increase with the increase of material thickness and air entrapped in the fabric. In fact, governing the sol-gel process at molecular level implies the possibility of controlling the formation of xerogel transition to obtain a porous silicon oxide material with the desired textural and surface chemical properties. Consequently, solgel based finishing is a useful approach to realize porous solid films filled with nanometer voids. Generally speaking, heat transfer takes place in the fibres with air entrapped inside the fabric structure acting as thermal insulator. If air entrapped in the fibres structure remains almost unchanged, due to the porous structure of the film, increasing the thickness of the fibres increases the thermal insulation as well. This will also explain the tendency of all of the tested fabrics thermal properties to stabilize, as for a certain concentration, the maximum amount of chemical being pickedup during treatment is reached. A further increase in concentration will not produce a further increase in chemical pickup and thus a relevant modification in the textile performances.

\section{Conclusions}

An experimental approach based on IR Thermometry has been applied for thermal properties characterization of a wide variety of cotton fabrics of different weave structure, as well as for the analysis of the influence of sol-gel finishing GPTMS concentration. All the collected data generally agreed with open literature available results, even if not so much information exists on the influence of weave structure on fabric thermal properties. From the presented results it was found that, for each tested CO weave, all data are well correlated with fabric density, with thermal conductivity linearly increasing with $\rho$. Moreover, thermal absorption progressively increased from piqué to plain up to satin-weave, the latter thus presenting the cooler feeling. Considering the influence of solgel based finishing, all tested CO fabrics presented a similar behavior, with all thermal properties variation initially increasing with rising chemical concentration and then stabilizing. In particular, for all the tested GPTMS concentrations, a reduction in thermal conductivity and thus an increase in thermal resistance were observed. In particular, the highest density fabric CO-3 showed the most important influence of finishing, probably due to its ability to pick-up more chemicals.

\section{Competing Interests}

The authors declare that there is no competing interests regarding the publication of this paper.

\section{Acknowledgments}

The authors would like to thank Dr. Maria Rosaria Plutino (ISMN-CNR) for TGA measurements and Mr. Ezio Carissoni (ITIS Paleocapa, Bergamo, Italy) for the technical support in the weave characterization of cotton samples.

\section{References}

[1] J. Alongi, J. Tata, F. Carosio, G. Rosace, A. Frache, and G. Camino, "A comparative analysis of nanoparticle adsorption as fire-protection approach for fabrics," Polymers, vol. 7, no. 1, pp. 47-68, 2015.

[2] G. Rosace and R. Canton, "Influence of low-temperature plasma conditions on wicking properties of PA/PU knitted fabric," Journal of Applied Polymer Science, vol. 107, no. 6, pp. 3702-3706, 2008.

[3] G. Rosace, R. Canton, and C. Colleoni, "Plasma enhanced CVD of $\mathrm{SiOxCyHz}$ thin film on different textile fabrics: influence of exposure time on the abrasion resistance and mechanical properties," Applied Surface Science, vol. 256, no. 8, pp. 2509-2516, 2010.

[4] C. Colleoni, I. Donelli, G. Freddi, E. Guido, V. Migani, and G. Rosace, "A novel sol-gel multi-layer approach for cotton fabric finishing by tetraethoxysilane precursor," Surface and Coatings Technology, vol. 235, pp. 192-203, 2013.

[5] B. Mahltig, H. Haufe, and H. Böttcher, "Functionalisation of textiles by inorganic sol-gel coatings," Journal of Materials Chemistry, vol. 15, no. 41, pp. 4385-4398, 2005.

[6] B. Mahltig and T. Textor, "Silver containing sol-gel coatings on polyamide fabrics as antimicrobial finish-description of a technical application process for wash permanent antimicrobial effect," Fibers and Polymers, vol. 11, no. 8, pp. 1152-1158, 2010.

[7] A. Farouk, T. Textor, E. Schollmeyer, A. Tarbuk, and A. M. Grancacic, "Sol-gel derived inorganic-organic hybrid polymers filled with $\mathrm{ZnO}$ nanoparticles as ultraviolet protection finish for textiles," Autex Research Journal, vol. 9, no. 4, pp. 114-120, 2009.

[8] B. Mahltig and T. Textor, "Combination of silica sol and dyes on textiles," Journal of Sol-Gel Science and Technology, vol. 39, no. 2, pp. 111-118, 2006.

[9] A. C. Aķsit and N. Onar, "Leaching and fastness behavior of cotton fabrics dyed with different type of dyes using sol-gel process," Journal of Applied Polymer Science, vol. 109, no. 1, pp. 97-105, 2008.

[10] K. S. Huang, Y. H. Nien, K. C. Hsiao, and Y. S. Chang, "Application of $\mathrm{DMEU} / \mathrm{SiO}_{2}$ gel solution in the antiwrinkle finishing of cotton fabrics," Journal of Applied Polymer Science, vol. 102, no. 5, pp. 4136-4143, 2006.

[11] C. Colleoni, E. Guido, V. Migani, and G. Rosace, "Hydrophobic behaviour of non-fluorinated sol-gel based cotton and polyester fabric coatings," Journal of Industrial Textiles, vol. 44, no. 6, pp. 815-834, 2015.

[12] M. Caldara, C. Colleoni, E. Guido, V. Re, and G. Rosace, "Development of a textile-optoelectronic $\mathrm{pH}$ meter based on hybrid xerogel doped with Methyl Red," Sensors and Actuators B: Chemical, vol. 171-172, pp. 1013-1021, 2012.

[13] R. Poli, C. Colleoni, A. Calvimontes, H. Polášková, V. Dutschk, and G. Rosace, "Innovative sol-gel route in neutral hydroalcoholic condition to obtain antibacterial cotton finishing by zinc precursor," Journal of Sol-Gel Science and Technology, vol. 74, pp. 151-160, 2014.

[14] J. Alongi, C. Colleoni, G. Rosace, and G. Malucelli, "The role of pre-hydrolysis on multi step sol-gel processes for enhancing the flame retardancy of cotton," Cellulose, vol. 20, no. 1, pp. 525-535, 2013.

[15] G. Brancatelli, C. Colleoni, M. R. Massafra, and G. Rosace, "Effect of hybrid phosphorus-doped silica thin films produced by sol-gel method on the thermal behavior of cotton fabrics," 
Polymer Degradation and Stability, vol. 96, no. 4, pp. 483-490, 2011.

[16] J. Alongi, C. Colleoni, G. Rosace, and G. Malucelli, "Phosphorus- and nitrogen-doped silica coatings for enhancing the flame retardancy of cotton: synergisms or additive effects?" Polymer Degradation and Stability, vol. 98, no. 2, pp. 579-589, 2013.

[17] J. Alongi, C. Colleoni, G. Rosace, and G. Malucelli, "Thermal and fire stability of cotton fabrics coated with hybrid phosphorus-doped silica films," Journal of Thermal Analysis and Calorimetry, vol. 110, no. 3, pp. 1207-1216, 2012.

[18] S. Güneşoğlu, B. Meric, and C. Güneşoğlu, "Thermal contact properties of 2-yarn fleece knitted fabrics," Fibres \& Textiles in Eastern Europe, vol. 13, no. 2, pp. 46-50, 2005.

[19] M. J. Pac, M.-A. Bueno, M. Renner, and S. El Kasmi, "Warmcool feeling relative to tribological properties of fabrics," Textile Research Journal, vol. 71, no. 9, pp. 806-812, 2001.

[20] N. Özdil, A. Marmarali, and S. D. Kretzschmar, "Effect of yarn properties on thermal comfort of knitted fabrics," International Journal of Thermal Sciences, vol. 46, no. 12, pp. 1318-1322, 2007.

[21] N. Uçar and T. Yilmaz, "Thermal properties of $1 \times 1,2 \times 2,3 \times 3$ rib knit fabrics," Fibres \& Textiles in Eastern Europe, vol. 12, no. 3, pp. 34-38, 2004.

[22] UNI EN 31092, Textiles-Determination of Physiological Properties-Measurement of Thermal and Water-Vapour Resistance under Steady-State Conditions (Sweating Guarded-Hotplate Test), 1996.

[23] T. S. Sokolovskaya, "Measurement of the thermal conductivity coefficient of textile materials by the regular cooling regime method," Fibre Chemistry, vol. 37, no. 1, pp. 59-62, 2005.

[24] L. Hes, "New achievements in the area of the objective evaluation of thermal insulation and thermal-contact properties of textiles," in Proceedings of the 3rd Asian Textile Conference (ATC '95), vol. 2, pp. 1201-1203, Hong Kong, September 1995.

[25] I. Frydrych, G. Dziworska, and J. Bilska, "Comparative analysis of the thermal insulation properties of fabrics made of natural and man-made cellulose fibres," Fibres \& Textiles in Eastern Europe, vol. 10, no. 4, pp. 40-44, 2002.

[26] M. Venkataraman, R. Mishra, J. Militky, and L. Hes, "Aerogel based nanoporous fibrous materials for thermal insulation," Fibers and Polymers, vol. 15, no. 7, pp. 1444-1449, 2014.

[27] M. Gustavsson and L. Hälldahl, “Thermal conductivity measurements of thin insulating layers deposited on high-conducting sheets," International Journal of Thermophysics, vol. 27, no. 1, pp. 195-208, 2006.

[28] J. Y. Hu, Y. Li, K. W. Yeung, and S. X. Wang, "Characterization of thermal radiation properties of polymeric materials," Polymer Testing, vol. 25, no. 3, pp. 405-412, 2006.

[29] D. Romeli, G. Barigozzi, S. Esposito, G. Rosace, and G. Salesi, "High sensitivity measurements of thermal properties of textile fabrics," Polymer Testing, vol. 32, no. 6, pp. 1029-1036, 2013.

[30] ISO, "Textiles-determination of thickness of textiles and textile products," ISO 5084, 1996.

[31] UNI EN 12127, "Textiles-fabrics-determination of mass per unit area using small samples," 1997.

[32] M. Matusiak, "Investigation of the thermal insulation properties of multilayer textiles," Fibres \& Textiles in Eastern Europe, vol. 14, no. 5, pp. 98-102, 2006.

[33] B. Simoncic, B. Tomsic, B. Orel, and I. Jerman, "Sol-gel technology for chemical modification of textiles," in Surface Modification Systems for Creating Stimuli Responsiveness of Textiles, D.
Jocic, Ed., chapter 3, pp. 17-34, University of Twente, Enschede, The Netherlands, 2010.

[34] R. Tian, O. Seitz, M. Li, W. Hu, Y. J. Chabal, and J. Gao, "Infrared characterization of interfacial Si-O bond formation on silanized flat $\mathrm{SiO}_{2} / \mathrm{Si}$ Surfaces," Langmuir, vol. 26, no. 7, pp. 4563-4566, 2010.

[35] J. Vasiljević, M. Gorjanc, B. Tomšič et al., “The surface modification of cellulose fibres to create super-hydrophobic, oleophobic and self-cleaning properties," Cellulose, vol. 20, no. 1, pp. 277289, 2013.

[36] I. Sumirat, Y. Ando, and S. Shimamura, "Theoretical consideration of the effect of porosity on thermal conductivity of porous materials," Journal of Porous Materials, vol. 13, no. 3, pp. 439443, 2006.

[37] N. Oğlakcioğlu and A. Marmarali, “Thermal comfort properties of some knitted structures," Fibres \& Textiles in Eastern Europe, vol. 15, no. 5-6, pp. 64-65, 2007.

[38] G. Havenith, "The interaction between clothing insulation and thermoregulation," Exogenous Dermatology, vol. 1, pp. 221-230, 2002. 

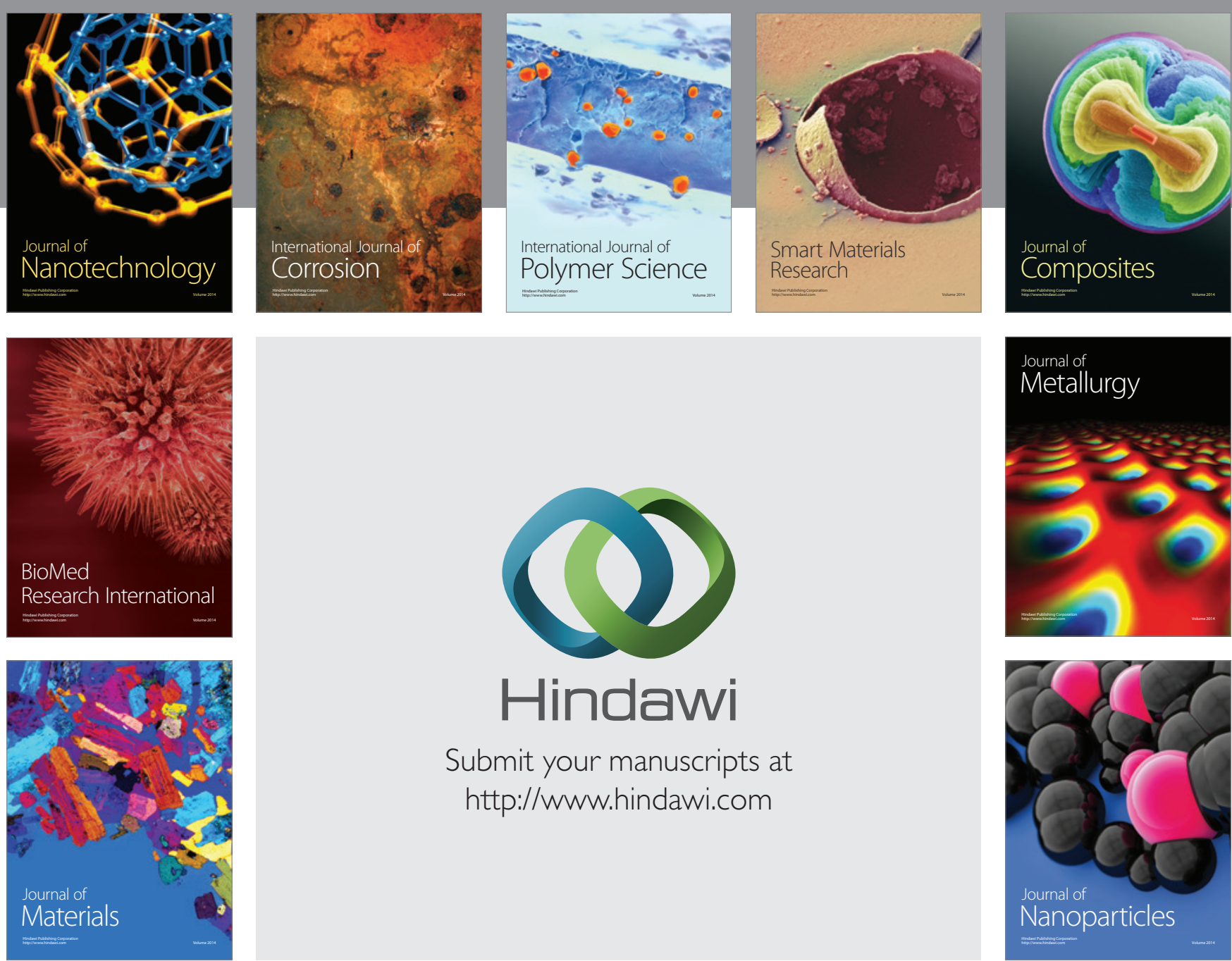

\section{Hindawi}

Submit your manuscripts at

http://www.hindawi.com

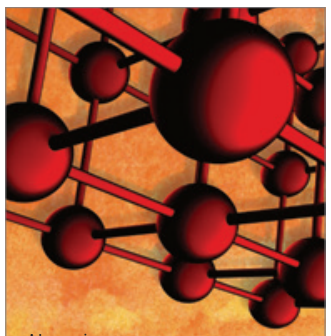

Materials Science and Engineering
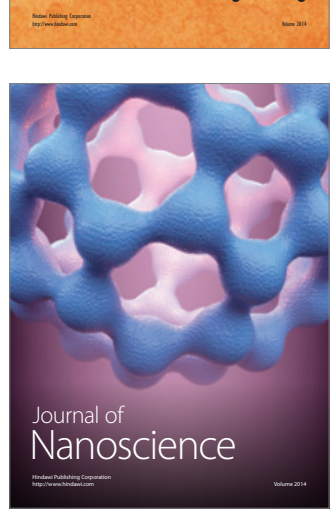
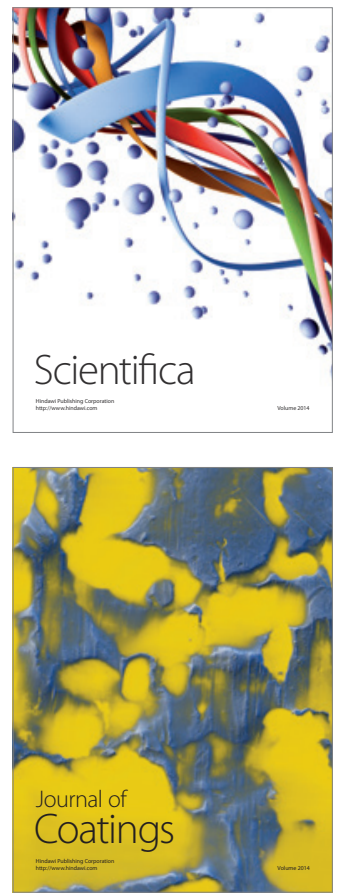
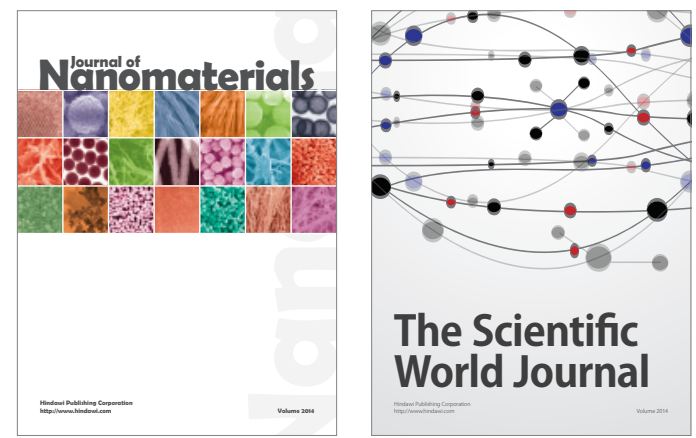

The Scientific World Journal
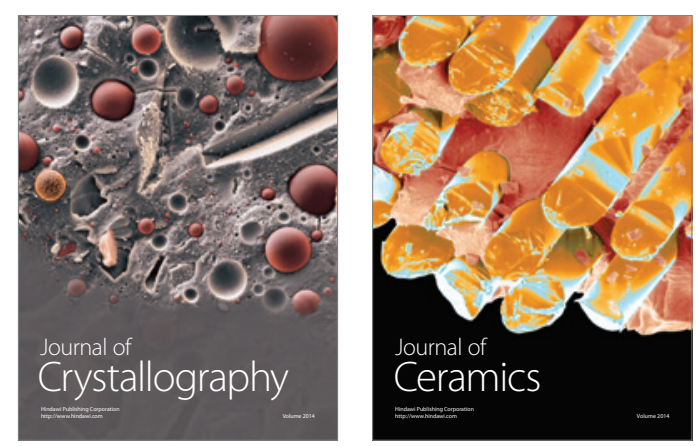
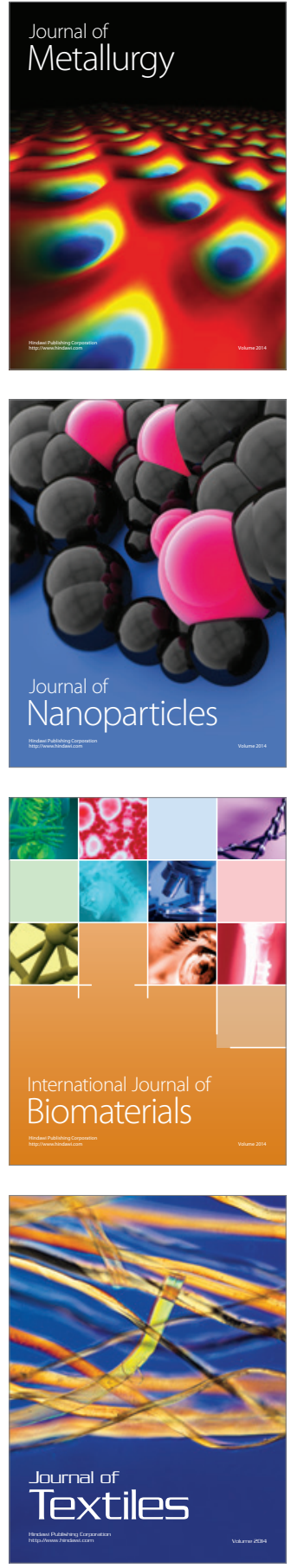